\section{P-56 SPICT-4ALL - A TOOL TO HELP EVERYONE IDENTIFY PEOPLE WHO MAY NEED PALLIATIVE AND SUPPORTIVE CARE}

'Lawrence Pike, 'Louise Price, ${ }^{2}$ Kirsty Boyd. 'St Barnabas Hospice, Lincolnshire, UK; ${ }^{2}$ University of Edinburgh, Edinburgh, UK

10.1136/bmjspcare-2017-hospice.83

Background Existing palliative care identification tools focus on health professionals. This has resulted in people with frailty, long-term conditions and organ failure being under-represented on GP palliative care registers. Listening to families and staff working in social care we recognised that they could identify decline, but lacked a common language to discuss this with a health professional.

Aims To design a tool for social carers, family and patients to help them identify more people who could benefit from supportive and palliative care. To empower them by writing this tool in accessible language so they can express their concerns about unmet needs to health professionals.

Methods We identified the Supportive and Palliative Care Indicators Tool (SPICT http://www.spict.org.uk) as a starting point after discussions with the programme lead. SPICT is an internationally recognised, evidence-based tool that uses established clinical indicators of deteriorating health for identification. We created a new version of SPICT and circulated this to 14 public groups in Lincolnshire. These consisted of over 300 members and represented a wide variety of interest. Based on consultation and feedback over several cycles, SPICT in 'nonmedical' language was developed. Only a few medical terms with no suitable equivalent remain. The SPICT programme team in Edinburgh and colleagues who are part of the online SPICT community also contributed to the final version. We now have a version acceptable to all potential users which we called SPICT-4ALL

Results SPICT-4ALL was published in June 2017. It is designed to make it easier for everyone to recognise and talk about signs that a person's overall health may be declining and consider anticipatory/advance care planning. It will improve identification of people with non-cancer illnesses in particular and empower families and carers in all settings.

\section{P-57 HOSPICE CARE FOR DEPRIVED AREAS - A LOCAL REVIEW OF THE EQUITY OF HOSPICE SERVICES}

${ }^{1}$ Katie Jerram, ${ }^{2}$ Richard Wagland, ${ }^{1} \mathrm{P}$-J Morey, ${ }^{1}$ Steve Plenderleith, ${ }^{1}$ Ruth White. ${ }^{1}$ Rowans Hospice, Waterlooville, UK: ${ }^{2}$ University of Southampton, Southampton, UK

\subsection{6/bmispcare-2017-hospice.84}

Background A recent report commissioned by Marie Curie found significant inequalities at the national level in the provision of palliative care across several domains, including social deprivation. Given the national inequalities, it is important to explore local variations in service use. Our hospice accepts referrals from areas including some of the $20 \%$ most deprived in the country.

Aim To determine whether social deprivation influences service uptake at a hospice in south east England.

Method A review of computerised records was conducted for all patients $(n=634)$ referred to the hospice inpatient unit or hospice at home service over a 12 month period (01/10/1430/09/15). Indices of Multiple Deprivation (IMD) data were used to identify patients from the most deprived quintile.
Data collected included demographic background, diagnosis, and referrer, and median scores were compared between the overall patient population and most deprived for duration of service use, preferred and actual place of death.

Results 14\% ( $n=107)$ of referred patients were from the most socially deprived IMD quintile of the population. Overall access to hospice services appeared broadly equitable between groups. For patients from the most deprived areas, median time under the care of hospice at home was lower (three vs five days). Once admitted, a stay over 21 days was more likely in the most deprived areas (25\% vs 19\%). Preferred place of death (PPD) was less likely to be recorded for the most deprived (68\% vs. 63\%) and home death was less likely (47\% vs. 50\%). PPD was achieved more commonly in those from deprived areas (87\% vs $82 \%)$ although place of death was less likely to be recorded. Full statistical analysis to follow.

Conclusions Despite small variations, service use at our hospice appears less inequitable on the basis of social deprivation than the national picture. Investigating local audit data can provide insights regarding current variations between regions of the UK, and these findings require further investigation.

\section{P-58 HOSPICE CARE FOR MARGINALISED PEOPLE - THE SAFE HARBOUR APPROACH}

Jane Carpenter. St Helena Hospice, Colchester, UK

10.1136/bmjspcare-2017-hospice.85

Background Access to palliative care nationally is inequitable (Sleeman, 2016), with recognition that marginalised people do not receive hospice care in the way that other groups do (CQC, 2016). Our hospice strategic aim is to reach unmet need and address inequality of access. Locally, groups identified to have unmet needs are: the homeless community, substance misusers, adults with enduring mental health issues, patients from minority ethnic groups, and transgender patients.

Approach The 'Safe Harbour' project was set up to address this unmet need. Those involved:

- Made themselves visible and approachable by attending homeless service drop-ins, addiction services, community network groups, beach cleans, food banks and health forums.

- Listened to our local community, service users, community groups and voluntary organisations, and carried out a detailed needs assessment. This demonstrated that we were prepared to talk openly about what we already do, to offer support to community members with unmet palliative and end of life care needs.

- Ensured that the hospice team were ready and competent to care for people with a wide spectrum of medical and psychosocial need.

- Worked with other key providers to ensure collaborative, effective support by those professionals best placed to care, including social care, mental health services, national and local charities.

- Case-management of the most complex marginalised palliative patients.

Outcome: We have established a service to support the marginalised population in our local area. One of the measures of the success of this service has been an increase from one to ten 